\title{
Isolation and Characterization of a Second Lectin (SNA-II) Present in Elderberry (Sambucus nigra L.) Bark ${ }^{1}$
}

\author{
Hanae Kaku, Willy J. Peumans, ${ }^{*}$ and Irwin J. Goldstein ${ }^{2}$ \\ Department of Biological Chemistry, University of Michigan, Ann Arbor, Michigan 48109, and *Laboratorium voor \\ Plantenbiochemie, Katholieke Universiteit Leuven, Willem de Croylaan 42, B-3030 Leuven (Heverlee), Belgium
}

Received June 29, 1989, and in revised form October 24, 1989

\begin{abstract}
A second lectin (SNA-II) has been isolated from elderberry (Sambucus nigra L.) bark by affinity chromatography on immobilized asialo-glycophorin. This lectin is a blood group nonspecific glycoprotein containing $\mathbf{7 . 8 \%}$ carbohydrate and which is rich in asparagine/aspartic acid, glutamine/glutamic acid, glycine, valine, and leucine. Gel filtration on Superose 12 gave a single symmetrical peak corresponding to $M_{\mathrm{r}}, 51,000$; SDSacrylamide electrophoresis gave a single polypeptide, $M_{\mathrm{r}}, \mathbf{3 0 , 0 0 0}$. Hence SNA-II appears to be a homodimer. The lectin is a Gal/GalNAc-specific lectin which is precipitated by glycoproteins containing GalNActerminated oligosaccharide chains (e.g., asialo-ovine submaxillary and hog gastric mucins), and by glycoproteins and polysaccharides having multiple terminal nonreducing D-galactosyl groups as occur in asialoglycophorin, asialo-laminin and Type 14 pneumococcal polysaccharide. The carbohydrate binding specificity of SNA-II was studied by sugar hapten inhibition of the asialo-glycophorin precipitation reaction. The lectin's binding site appears to be most complementary to GalNAc linked $\alpha$ to the C-2, C-3, or C-6 hydroxyl group of galactose. These disaccharide units are approximately 100 times more potent than melibiose, 60 times more potent than $N$-acetyllactosamine, and 30 times more potent than lactose. Interestingly, the blood group Aactive trisaccharide containing an L-fucosyl group linked $\alpha$ 1-2 to galactose was 10-fold pourer as an inhibitor than the parent oligosaccharide (GalNAc $\alpha$ 1-3Gal), suggesting steric hindrance to binding by the $\alpha$-L-fucosyl group; this explains the failure of the lectin to exhibit blood group A specificity. 1990 Academic Press, Inc.
\end{abstract}

A large number of plant lectins purified from seeds (especially legume seeds), leaves, tubers, and fruits have

\footnotetext{
${ }^{1}$ This research was supported in part by NIH Grant GM 29470.

${ }^{2}$ To whom correspondence should be addressed.
}

been described. They all have specific binding sites for carbohydrate groups and may be employed for the detection, isolation, and characterization of glycoconjugates. Lectins may also be used for the localization of carbohydrates on the surface of animal, plant, and microbial cells. A detailed study of the sugar-binding specificity of a lectin is necessary before it may prove useful in investigations of biochemical and biomedical phenomena.

In recent years, it has become clear that some plants contain two or more lectins with different sugar binding specificity, e.g., Grifforia simplicifolia (GS I, II, and IV) (1-3), Laburnum alpinum (I, II) (4), Phaseolus vulgaris (PHA-E, PHA-L) (5), Ulex europaeus (I, II) (6), Vicia cracca (7), Vicia villosa (8), Wistaria floribunda $(9,10)$.

The bark of the clderberry (Sambucus nigra L.), which belongs to the family Caprifoliaceae, also contains multiple lectins. The first lectin (SNA-I) ${ }^{3}$ reported present in elderberry bark was purified by affinity chromatography on immobilized fetuin (11), and its detailed carbohydrate binding properties were reported (12). This lectin is a tetrameric glycoprotein $\left(M_{\mathrm{r}}, 1.4 \times 10^{5}\right)$ consisting of two different subunits, which recognizes Neu5 Ac $(\alpha 2-6) \mathrm{Gal} / \mathrm{GalNAc}$ sequences.

We describe herein the isolation of a second lectin (SNA-II) from the same elderberry bark tissue, its physical-chemical characterization, and its sugar-binding specificity properties; we also report on a comparison of the properties of the two lectins from elderberry bark.

\section{MATERIALS AND METHODS}

Purification of a second lectin from elderberry bark. A second elderberry bark lectin (SNA-II) was partially purified from bark extracts

\footnotetext{
${ }^{3}$ Abbreviation used: SNA-I, the first lectin from Sambucus nigra; SNA-II, the second lectin from Sambucus nigra; D-GalNAc, $N$-acetylD-galactosamine; D-GIcNAc, $N$-acetyl-D-glucosamine; Fru, fructose; L-Fuc, L-fucose; Neu5Ac, $N$-acetylneuraminic acid; BSA, bovine serum albumin; SDS, sodium dodecyl sulfate; $\mathrm{PBS}$, phosphate-buffered saline ( $10 \mathrm{~mm} \mathrm{Na}$ phosphate containing $150 \mathrm{~mm} \mathrm{NaCl}$, pII 7.2, $0.1 \mathrm{mM}$ $\mathrm{CaCl}_{2}$, and $0.04 \% \mathrm{NaN}_{3}$ ).
} 
by affinity chromatography on immobilized porcine stomach mucin. Fresh bark $(100 \mathrm{~g})$ was homogenized and extracted in PBS, centrifuged $(15 \mathrm{~min} ; 10,000 \mathrm{~g})$, and passed through a column of immobilized fetuin in order to remove the Neu5Ac $(\alpha 2-6) \mathrm{Gal} / \mathrm{GalNAc}$ binding SNA-I $(0.24 \mathrm{~g}, 3.9 \%$ of total protein content) eluted with $20 \mathrm{mM} 1,3-$ diaminopropane according to the procedure of Broekaert et al. (11). The SNA-I and SNA-II activities were monitored by the agglutination assay described in detail below. The PBS passthrough fraction from fetuin-Sepharose 4B, which contained only the SNA-II activity, was loaded onto a mucin-Sepharose $4 \mathrm{~B}$ column ( $50 \mathrm{ml}$ bed volume) and, after washing with buffer, the bound SNA-II $(0.13 \mathrm{~g}, 2.1 \%$ of total protein content) was displaced with unbuffered $20 \mathrm{mM} \mathrm{1,3-diamino-}$ propane. Finally, this preparation was purified to homogeneity by affinity chromatography on immobilized asialo-glycophorin. After washing the column with PBS, purified SNA-II was obtained by elution with PBS containing $0.2 \mathrm{M}$ lactose, followed by dialysis against PBS.

The SNA-I activity was examined by agglutination assay with a pigeon erythrocyte suspension containing $1 \mathrm{~mm}$ GalNAc to inhibit SNA-II activity; SNA-II has a very low agglutination activity with pigeon erythrocytes (about 800 times less than that of SNA-I). The agglutination activity of SNA-II was conducted using a human blood group A erythrocyte suspension in the presence of $500 \mu \mathrm{g} / \mathrm{ml}$ fetuin to inhibit SNA-I activity. One unit of agglutination is defined as the amount of lectin required for the agglutination of $1 \mathrm{ml}$ of a $1 \%$ suspension of erythrocytes.

Saccharides and glycoproteins. Various monosaccharides and their derivatives were purchased from Sigma Chemical Co. (St. Louis, MO) and Pfanstiehl Laboratories, Inc. (Waukegen, IL). D-Galactal was obtained from Raylo chemicals Ltd. (Alberta, Canada) and 2-deoxy-Dgalactose was from P-L Biochemicals Inc. (Milwaukee, WI). The following synthetic oligosaccharides, the structure of which are shown in Table IV, were generously provided by Dr. Jörgen Lönngren, University of Stockholm: Galß1-4GlcNAc $\beta 1-2$ Man: Penta 2.6; Hexa 3,6; Nona I; and Undeca. Gal $\beta 1-3$ GalNAc was purchased from Sigma. The disaccharides, GalNAc $\alpha 1-3 \mathrm{Gal}$, GalNAc $\alpha 1-6 \mathrm{Gal}$, GalNAc $\beta 1-6 \mathrm{Gal}$, GalNAc $\alpha 1-2 \mathrm{GalNAc}-\mathrm{O}-\left(\mathrm{CH}_{2}\right)_{8} \mathrm{CO}_{2} \mathrm{CH}_{3}$, and GalNAc $\alpha 1-3 \mathrm{GalNAc}-$ $\mathrm{O}-\left(\mathrm{CH}_{2}\right)_{8} \mathrm{CO}_{2} \mathrm{CH}_{3}$ were available from previous studies. Methyl 2-Omethyl- $\alpha$-D-galactopyranoside, methyl 2-O-acetyl- $\alpha$-D-galactopyranoside, methyl 2-benzamido-2-deoxy- $\alpha$-D-galactopyranoside and methyl 2-deoxy-2-p-nitrobenzamido- $\alpha$-D-galactopyranoside were synthesized by Dr. R. Kaifu as previously reported (13). The blood Type A trisaccharide and its trisaccharide-BSA conjugate were obtained from ChemBiomed Ltd. (Alberta, Canada). Stachyose was obtained from Aldrich Chemical Co., Inc. (Milwaukee, WI).

Glycophorin was prepared from human Type O erythrocytes by Dr. S. Rinderle of our laboratory using the phenol-water extraction method (14). Pneumococcal Type 14 polysaccharide was the gift of Dr. Peter A. Allen of the University of Rochester. Laminin isolated from the murine Engelbrath-Holm-Swarm sarcoma and asialolaminin obtained by treatment of laminin with neuraminidase (Clostridium perfringens) for $24 \mathrm{~h}$ at $37^{\circ} \mathrm{C}$ were prepared by Dr. R. Knibbs of our laboratory as previously reported (15).

General methods. Total protein and neutral sugars were determined by Lowry's method (16) and the phenol-sulfuric acid method (17), respectively. The analysis of sugar composition and amino terminal sequence analysis were performed by Dr. F. Perini of the University of Michigan $(18,19)$. Amino acid analysis was performed by the University of Michigan Protein Sequencing Facility using phenylthiocarbamyl amino acids derivatives (20).

Glycophorin was desialylated by heating with $0.1 \mathrm{M} \mathrm{H}_{2} \mathrm{SO}_{4}$ for $1 \mathrm{~h}$ at $80^{\circ} \mathrm{C}$, then dialyzed against distilled water (four times) and lyophilyzed. Agalacto Type 14 pneumococcal polysaccharide was prepared by Smith degradation as previously reported by Ebisu et al. (21).

Hemagglutination assays were performed at room temperature in microtiter plates (Dynatech Laboratories, Type V). Each well contained $25 \mu \mathrm{l}$ of serially diluted lectin solution and $50 \mu \mathrm{l}$ of $2 \%$ human
A, B, O, or rabbit erythrocyte suspension. Hemagglutination titer was determined $1 \mathrm{~h}$ after incubation at room temperature.

Quantitative precipitin and precipitin inhibition assay. Quantitative precipitin assays were carried out by a microprecipitin technique. Forty micrograms of SNA-II was mixed with varying amounts of glycoprotein or polysaccharide. After incubation at $37^{\circ} \mathrm{C}$ for $1 \mathrm{~h}$, the mixtures were kept at $4^{\circ} \mathrm{C}$ for 2 days, and centrifuged; protein in the precipitates was determined by Lowry's method (16) using BSA as standard.

Sugar inhibition of the precipitin reaction was carried out by adding increasing amounts of sugar or sugar derivatives to the lectin-asialoglycophorin system. The protein in the washed precipitates was determined hy the procedure of I cowry (16).

Determination of molecular weight of SNA-II. The molecular weight of SNA-II was determinated by gel filtration on a Pharmacia Superose 12 (Type 10/30) column equilibrated with PBS containing $0.1 \mathrm{M}$ galactose with aldolase $\left(M_{\mathrm{r}}, 160,000\right)$, BSA $\left(M_{\mathrm{r}}, 67,000\right)$, chymotrypsinogen A $\left(M_{\mathrm{r}}, 25,000\right)$, and cytochrome $c\left(M_{\mathrm{r}}, 12,500\right)$ being used as molecular weight standards.

Electrophoresis. Electrophoresis on polyacrylamide gel was performed at $\mathrm{pH} 4.3$ in $\beta$-alanine/acetic acid buffer (22). Polyacrylamide gel electrophoresis in the presence of SDS ( $10 \%$ gel) was performed according to Laemmli (23). Experiments were performed both in the presence and in the absence of $\beta$-mercaptoethanol.

\section{RESULTS}

Purification of SNA-II. Elderberry bark contains two different sugar-binding proteins: elderberry bark lectin I (SNA-I, which recognizes Neu5Ac( $\alpha 2-6) \mathrm{Gal} /$ GalNAc sequences) and elderberry bark lcctin II (SNA II). SNA-I was removed completely from extracts of elderberry bark by affinity chromatography on immobilized fetuin. SNA-II was isolated from the PBS passthrough fraction collected from the fetuin-Sepharose $4 \mathrm{~B}$ column by successive affinity chromatography on immobilized mucin followed by chromatography on asialoglycophorin-Sepharose 2B (Table I). SNA-II bound to the asialoglycophorin-Sepharose $2 \mathrm{~B}$ affinity column and was eluted with PBS containing $0.2 \mathrm{M}$ lactose (Fig. 1). The yield of purified lectin from this column was about $60 \%$ of the protein applied and represents $1.3 \%$ of the total extractable protein.

The electrophoretic homogeneity of SNA-II was established by electrophoresis on polyacrylamide gel at $\mathrm{pH}$ 4.3 (Fig. 2A). 'T'he molecular weight of SNA-II was determined to be 51,000 by gel filtration on a Superose 12 column in the presence of $0.1 \mathrm{M}$ galactose (Fig. 3). SDSpolyacrylamide gel electrophoresis of SNA-II in the presence or absence of $\beta$-mercaptoethanol gave a single protein-staining band with $M_{\mathrm{r}}, 30,000$ (Fig. 2B). These results suggest that SNA-II consists of two identical polypeptide chains.

The purified SNA-II agglutinated rabbit erythrocytes more strongly than human Type A, B, or O erythrocytes. The minimal concentrations required for agglutination of human and rabbit red cells was $62 \mu \mathrm{g} / \mathrm{ml}$ and $2 \mu \mathrm{g} / \mathrm{ml}$, respectively. 
TABLE I

Purification Scheme of SNA-II

\begin{tabular}{lcccc}
\hline \multicolumn{1}{c}{ Purification step } & $\begin{array}{c}\text { Total } \\
\text { volume } \\
(\mathrm{ml})\end{array}$ & $\begin{array}{c}\text { Total } \\
\text { protein } \\
(\mathrm{mg})\end{array}$ & $\begin{array}{c}\text { Total agglutination activity } \\
\text { (unit) }\end{array}$ & $\begin{array}{c}\text { Protein } \\
\text { recovery } \\
(\%)\end{array}$ \\
\hline $\begin{array}{l}\text { Crude extract } \\
\text { Affinity chromatography }\end{array}$ & 1000 & 6200 & $1,250,000$ & 300,000 \\
$\quad$ (a) Fetuin-Sepharose 4B & & & 100 \\
$\quad$ Bound fraction & 50 & 240 & $1,250,000$ & 0 \\
$\quad$ Passthrough fraction & 1200 & 6000 & 0 & 300,000 \\
(b) Mucin-Sepharose 4B & 100 & 130 & 0 & 300,000 \\
(c) Asialo-glycophorin-Sepharose 2B & 60 & 80.6 & 0 & 174,000 \\
\hline
\end{tabular}

The results of amino acid and carbohydrate analysis of SNA-II are shown in Table II. The amino acid and carbohydrate compositions were computed on a molar percentage basis and were compared with the data of the first lectin (SNA-I) from elderberry bark (11). SNA-II is rich in asparagine/aspartic acid, glycine, glutamine/ glutamic acid, leucine, and valine; contains little histidine; and contains three cysteine residues per polypeptide chain. Carbohydrate analysis showed the lectin to be a glycoprotein containing $7.8 \%$ carbohydrate consisting of glucosamine, mannose, and small amounts of fucose and galactose.

The N-terminal amino acid sequence data for SNA-II are shown in Fig. 4 and compared with that of the B chain of ricin D (24).

Precipitation assay. The precipitin curves of SNA-II with glycoconjugates and polysaccharides are shown in

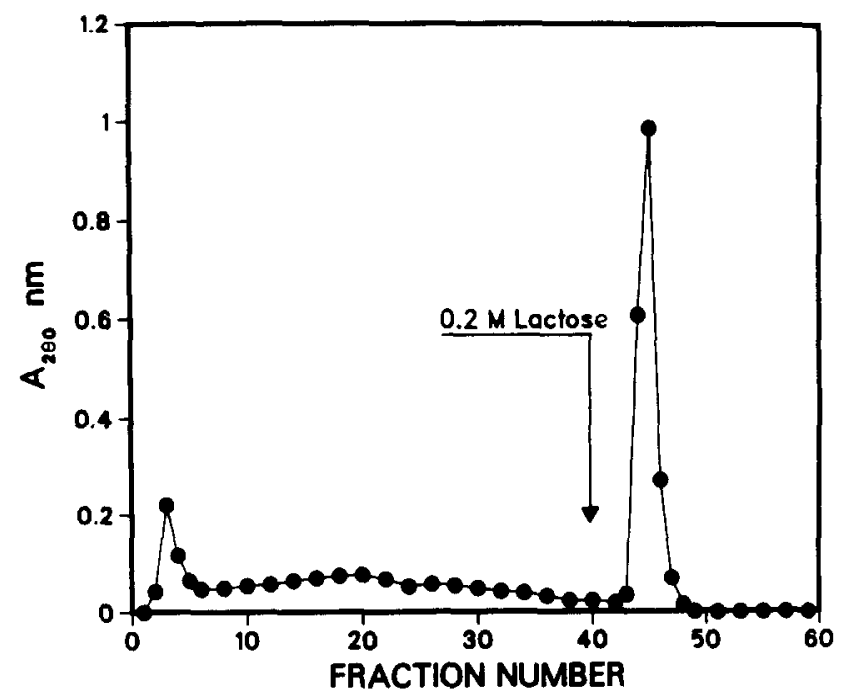

FIG. 1. Elution profile of SNA-II on asialo-glycophorin-Sepharose 2B. Lectin in PBS was applied to the column, washed with PBS, then cluted with $0.2 \mathrm{M}$ lactose.

Fig. 5. Asialo-ovine submaxillary and hog gastric mucin, highly substituted with terminal $\alpha$-D-GalNAc groups, were precipitated by SNA-II, but bovine submaxillary mucin, which contains ca. $12 \%$ sialic acid, failed to form a precipitate with the lectin. Asialo-glycophorin and asialo-laminin gave pronounced precipitation reactions with SNA-II; however, their sialylated derivatives were not precipitated by SNA-II. Type 14 pneumococcal polysaccharide, which has repeating units of $-6[\mathrm{Gal} \beta 1-4]$ -

A

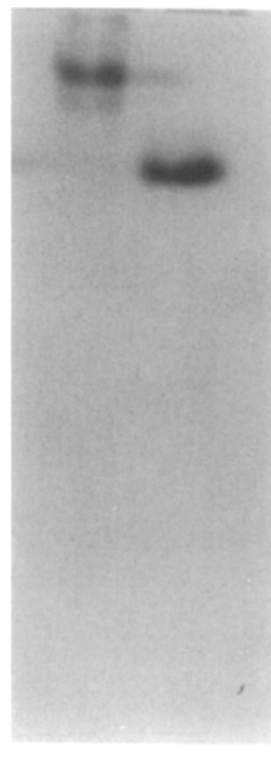

12

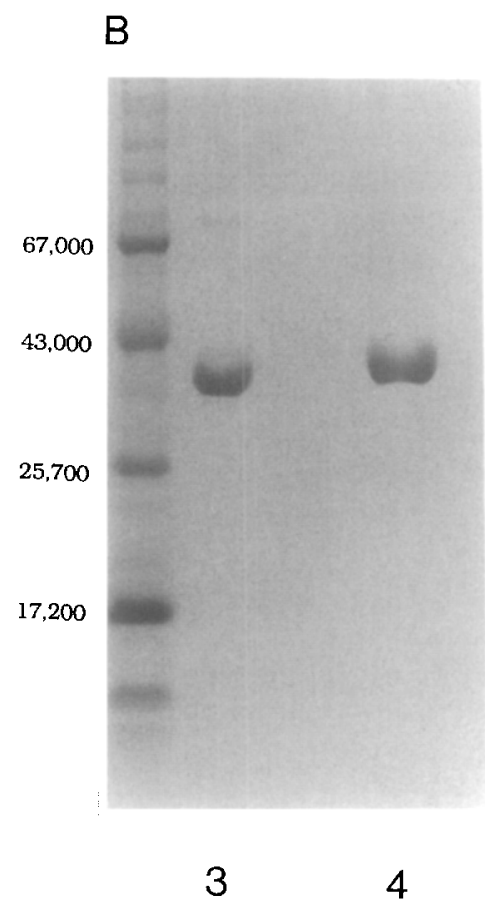

FIG. 2. Electrophoresis of lectin from elderberry bark. (A) Polyacrylamide gel electrophoresis $(\mathrm{pH} 4.3)$ of lectin $\mathrm{I}(1 ; 50 \mu \mathrm{g})$ and lectin II $(2 ; 50 \mu \mathrm{g})$ from elderberry bark. (B) SDS-polyacrylamide gel electrophoresis of SNA-II $(20 \mu \mathrm{g})$ in the presence (4) and absence (3) of $\beta$ mercaptoethanol. 


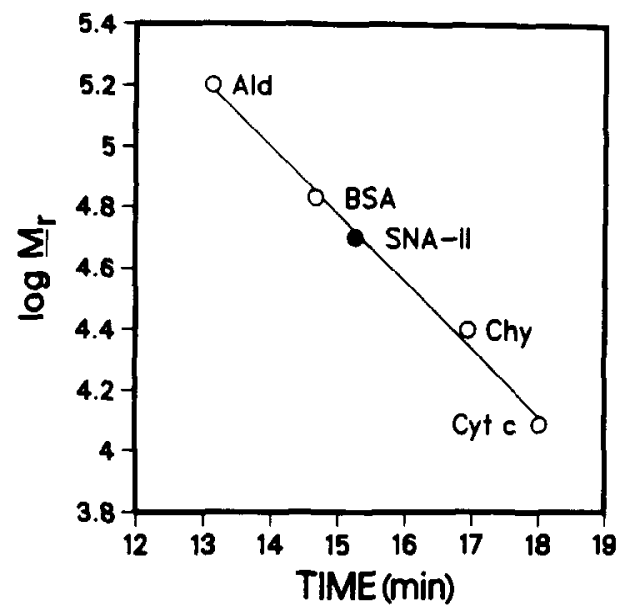

FIG. 3. Molecular weight of SNA-II by chromatography on a Pharmacia Superose 12 (Type 10/30) with PBS containing $0.1 \mathrm{M}$ galactose as running buffer. Molecular weight markers used were aldolase (Ald, $\left.M_{\mathrm{r}}, 160,000\right)$; BSA $\left(M_{\mathrm{r}}, 67,000\right)$; chymotrypsinogen A (Chy, $M_{\mathrm{r}}$, $25,000)$; cytochrome $c$ (Cyt c, $M_{\mathrm{r}}, 12,500$ ).

GlcNAc $\beta 1-3 \mathrm{Gal} \beta 1-4 \mathrm{Glc} \beta 1$ - (25), was also precipitated by SNA-II, but the Smith-degraded polysaccharide, [resulting in the cleavage of only terminal $\beta$-D-galactopyranosyl residues by controlled periodate oxidation and $\mathrm{NaBH}_{4}$ reduction followed by mild acid hydrolysis (21)] was not precipitated by SNA-II. Galactomannan isolated from guar gum reacted only slightly with SNA-II, and galactan from larch failed to form a precipitate with SNA-II. Furthermore, various synthetic BSA conjugates containing terminal D-galactose or $N$-acetyl-D-galactosamine units were not precipitated with SNA-II. These results suggested that the SNA-II lectin precipitates glycoproteins and polysaccharides having GalNAc-terminated oligosaccharides or a high density of terminal nonreducing D-galactosyl groups.

Inhibition of precipitin reaction by haptenic sugars. The carbohydrate binding specificity of SNA-II was studied by sugar hapten inhibition of precipitation by asialo-glycophorin and is presented in Tables III and IV. We already noted that this lectin has specific binding activity toward terminal D-galactosyl and $N$-acetyl-Dgalactosaminyl groups. D-Gulose, the C-3 epimer of galactose, and D-glucose (C-4 epimer) were poorer inhibitors than D-galactose. However, modifications at the C-2 position of galactose gave variable results: methyl 2 - $O$-methyl- $\alpha$-D-galactopyranoside was comparable to methyl $\alpha$-D-galactopyranoside in inhibitory potency whereas methyl 2-O-acetyl- $\alpha$-D-galactopyranoside was 10 times more potent; D-talose, the C-2 epimer of D-galactose, and 2-deoxy-D-galactose were three- and twofold, respectively, more potent than D-galactose. Moreover, D-fucose (6-deoxy-D-galactose) was a better inhibitor than D-galactose. These results suggested that
TABLE II

Amino Acid and Carbohydrate Composition of the Two Lectins from Elderberry Bark

\begin{tabular}{ccc} 
& \multicolumn{2}{c}{ Mol \% } \\
\cline { 2 - 3 } & SNA-II & SN - $^{a}{ }^{a}$ \\
\hline Amino acid & & \\
Asx & 14.0 & 10.8 \\
Thr & 6.1 & 7.6 \\
Ser & 6.5 & 7.4 \\
Glx & 7.7 & 8.6 \\
Pro & 4.9 & 4.9 \\
Gly & 9.0 & 6.3 \\
Ala & 6.2 & 5.0 \\
Val & 7.1 & 9.1 \\
Met & 2.3 & 1.2 \\
Ile & 6.2 & 4.6 \\
Leu & 7.2 & 8.7 \\
Tyr & 1.6 & 2.8 \\
Phe & 2.4 & 3.2 \\
His & 0.2 & 0.9 \\
Lys & 2.3 & 1.9 \\
Arg & 5.5 & 5.3 \\
Trp & nd & 1.6 \\
Cys & 2.8 & 2.1 \\
Sugar & & \\
Gal & 0.47 & 1.5 \\
Man & 2.4 & $5.6^{b}$ \\
Fuc & 0.52 & \\
GlcN & 4.4 & \\
\hline
\end{tabular}

${ }^{a}$ The data were recalculated (including carbohydrate) from Broekaert et al. (11).

${ }^{b}$ Neutral sugars.

the C-3 equatorial and C-4 axial hydroxyl groups of galactose are essential for binding to SNA-II.

The best monosaccharide inhibitor was $N$-acetyl-Dgalactosamine, which was 32 times more potent than Dgalactose $(18 \mu \mathrm{M}$ as compared with $580 \mu \mathrm{M})$.

Both the $\alpha$ - and the $\beta$-anomers of methyl and $p$-nitrophenyl $N$-acetyl-D-galactosaminides were 2 to 5 times more active than $N$-acetyl-D-galactosamine. On the other hand, methyl $\alpha$-D-galactosaminide and methyl $N$ -
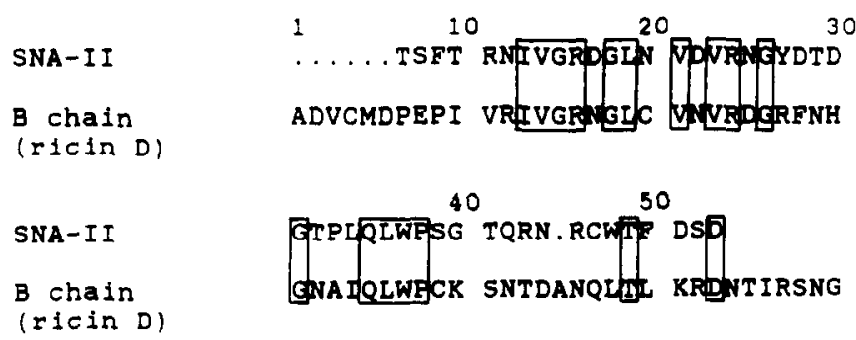

FIG. 4. N-Terminal amino acid sequence of SNA-II and B chain of ricin $\mathrm{D}$ (castor bean, (25)). 

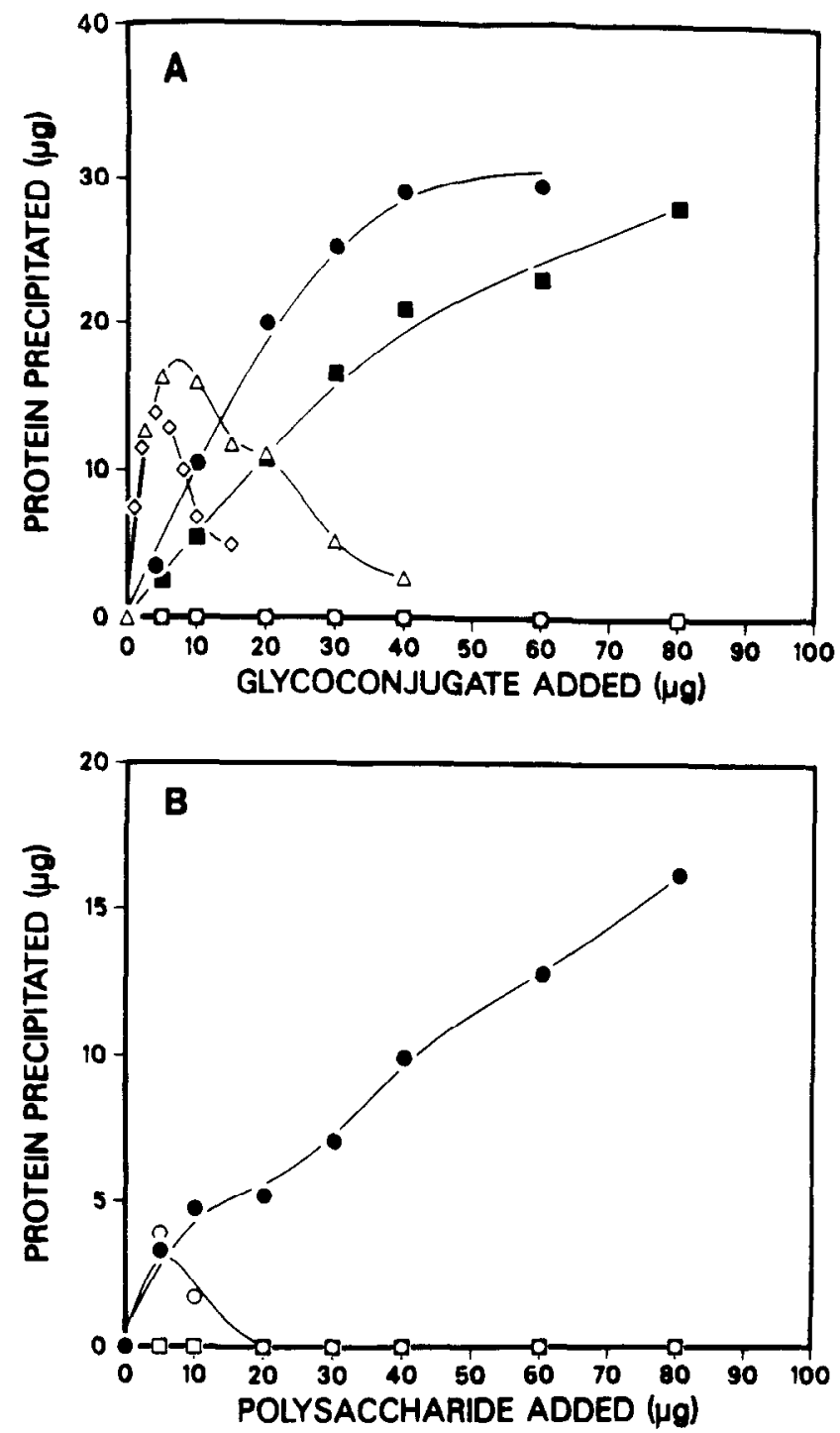

FIG. 5. Precipitation of glycoconjugates (A) and polysaccharides (B) by SNA-II. Details are given under Materials and Methods. (A) $\triangle$, hog gastric mucin; $\diamond$, asialo-ovine submaxillary mucin; $\bullet$, asialo-

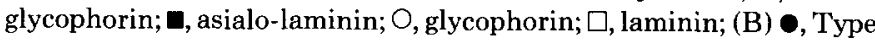
14 pneumococcal polysaccharide; $\square$, Type 14 pneumococcal polysaccharide modified by periodate oxidation; $O$, galactomannan (gran gum). SNA-II did not form precipitates with fetuin, asialo-fetuin, asialo- $\alpha_{1}$-acid glycoprotein, $p$-azophenyl $\alpha$-D-Gal-BSA, $p$-azophenyl $\beta$-D-Gal-BSA, $p$-azophenyl $\alpha$-D-GalNAc-BSA, $p$-azophenyl $\beta$-D-GalNAc-BSA, Gal $\beta 1$-3GalNAc $\alpha-B S A$, Gal $\beta 1-3$ GalNAc $\beta-B S A$, lactoside-BSA, lactosaminide-BSA, blood Type A trisaccharide-BSA, or galactan (larch).

acetyl- $\beta$-D-galactofuranosaminide had lower inhibitory potencies than $N$-acetyl-D-galactosamine. In addition methyl 2- $O$-acetyl- $\alpha$-D-galactopyranoside was a 3 to 20 times poorer inhibitor than methyl $2-N$-acyl $\alpha$-D-derivatives, e.g., methyl $\alpha$-D-GalNAc, methyl 2-benzamido-2deoxy- $\alpha$-D-Galp and methyl 2-deoxy-2-p-nitrobenzamido- $\alpha-D-G a l p$. These results suggest that the presence of the $\mathrm{N}$-acetyl group and the pyranose ring form are important requirements for binding to the lectin. Moreover, comparison of methyl $N$-acetyl- $\alpha$ - and $\beta$-D-galactosaminide with those of the corresponding $p$ nitrophenyl derivatives indicated that the hydrophobic group did not have an appreciable influence on the binding of these sugar glycosides to the protein. Nor did the synthetic methyl 2-benzamido-2-deoxy- $\alpha$-D-Galp and methyl 2-deoxy-2-p-nitrobenzamido- $\alpha$-D-Galp show an appreciable enhancement of inhibition potency when compared to methyl $\alpha$-D-GalNAcp.

Several oligosaccharides terminating in galactose or $N$-acetyl-D-galactosaminide were also studied. Of these, those containing nonreducing terminal $N$-acetyl-D-galactosaminyl units were the best inhibitors; e.g., GalNAc $\alpha 1-3 \mathrm{Gal}$, GalNAc $\alpha 1-6 \mathrm{Gal}$, GalNAc $\alpha 1-2 \mathrm{Gal}$. However, the Forssman disaccharide, GalNAc $\alpha 1-3$ GalNAc, was 10 times less potent than GalNAc $\alpha 1-3 \mathrm{Gal}$. Interestingly, the blood Type A trisaccharide (GalNAc $\alpha 1-3[\mathrm{~L}-$ Fuc $\alpha 1-2] \mathrm{Gal}$ ) was also 10 times poorer an inhibitor than GalNAc $\alpha 1-3 \mathrm{Gal}$. These results suggest that the $N$-acetyl group of the penultimate GalNAc in the Forssman antigen and the L-Fuc group in the Type A trisaccharide may act to sterically inhibit binding.

TABLE III

Inhibition of SNA-II Asialoglycophorin Precipitation by Monosaccharides

\begin{tabular}{|c|c|}
\hline Sugar & $\mu M$ required for $50 \%$ inhibition \\
\hline D-Gal & 580 \\
\hline Methyl $\alpha-\mathrm{D}-\mathrm{Gal}_{p}$ & 680 \\
\hline Methyl $\beta-\mathrm{D}-\mathrm{Gal}_{p}$ & 360 \\
\hline Methyl 2-O-methyl- $\alpha-\mathrm{D}-\mathrm{Gal}_{p}$ & 630 \\
\hline Methyl 2-O-acetyl- $\alpha$-D-Gal & 68 \\
\hline$p$-Nitrophenyl- $\alpha-\mathrm{D}-\mathrm{Gal}_{p}$ & 220 \\
\hline$p$-Nitrophenyl- $\beta-\mathrm{D}-\mathrm{Gal}_{p}$ & 120 \\
\hline 2-Deoxy-D-Gal & 250 \\
\hline D-Galactal & $0 \%$ inhibition at $20 \mathrm{mM}$ \\
\hline D-Talose (C-2 epimer) & 175 \\
\hline D-Gulose (C-3 epimer) & $38 \%$ inhibition at $50 \mathrm{mM}$ \\
\hline D-Glucose (C-4 epimer) & 45000 \\
\hline D-Fucose (6-Deoxy-D-Gal) & 450 \\
\hline D-GleNAc & $43 \%$ inhibition at $100 \mathrm{mM}$ \\
\hline Methyl $\beta-\mathrm{D}-\mathrm{Glc}_{p}$ & 54000 \\
\hline Methyl $\beta-\mathrm{D}-\mathrm{GlcNAc} \mathrm{c}_{\mathrm{p}}$ & $0 \%$ inhibition at $10 \mathrm{~mm}$ \\
\hline D-GalNAc & 18 \\
\hline Methyl $\alpha-\mathrm{D}$-GalNAc $\mathrm{Ac}_{p}$ & 8.6 \\
\hline Methyl $\beta$-D-GalNAc $c_{p}$ & 7.6 \\
\hline Methyl $\alpha-\mathrm{D}-\mathrm{GalN} \mathrm{N}_{p}$ & $24 \%$ inhibition at $0.5 \mathrm{~mm}$ \\
\hline Methyl $\beta$-D-GalNAc ${ }_{f}$ & $38 \%$ inhibition at $1.5 \mathrm{mM}$ \\
\hline Methyl 2-benzamido-2- & \\
\hline deoxy- $\alpha-\mathrm{D}-\mathrm{Gal}_{p}$ & 3.8 \\
\hline Methyl 2-deoxy-2-p- & \\
\hline nitrobenzamido- $\alpha-\mathrm{D}-\mathrm{Gal}_{p}$ & 3.2 \\
\hline$p$-Nitrophenyl- $\alpha$-D-GalNAc ${ }_{p}$ & 7.3 \\
\hline$p$-Nitrophenyl- $\beta$-D-GalNAc ${ }_{p}$ & 3.8 \\
\hline
\end{tabular}


TABLE IV

Inhibition of SNA-II-Asialoglycophorin Precipitation by Oligosaccharides



On the other hand, the inhibitory potency of oligosaccharides carrying terminal Gal units were 2 to 13 times greater than that of D-Gal but 1.5 to 20 times poorer than that of those having terminal GalNAc units. Various branched oligosaccharides having terminal Gal residues such as Penta 2,6; Hexa 3,6; Nona I; and Undeca (Table IV) were 2 to 8 times better inhibitors than oligosaccharides containing a single terminal galactosyl group. Neu5Ac $\alpha 2-6$ lactose and Neu5Ac $\alpha 2-3$ lactose were poorer inhibitors than lactose.

\section{DISCUSSION}

Asialo-glycophorin-Sepharose was an effective affinity chromatographic matrix for the final purification of the second lectin (SNA-II) from elderberry bark. SNAII did not bind to Sepharose or Synsorb beads containing $\beta$-GalNAc, Gal $\beta 1$-3GalNAc, Gal $\beta 1-4 \mathrm{GalNAc}$, or GalNAc $\alpha 1-3[$ L-Fuc $\alpha 1-2]$ Gal units.

Comparison of the $N$-terminal amino acid sequence of SNA-II with some plant lectins revealed the greatest homology with the $B$ chain of ricin $D$, which is a galactose $/ N$-acetylgalactosamine-specific lectin. There were 15 identical amino acid residues in positions 10 to 40 , showing approximately $37 \%$ homology (Fig. 4).

Precipitin inhibition studies of SNA-II with asialoglycophorin show this lectin to possess a higher specific 
TABLE V

Inhibition by Various Sugars of Lectins from Elderberry(Asialo)Glycophorin Precipitation

\begin{tabular}{|c|c|c|}
\hline \multirow[b]{2}{*}{ Sugar } & \multicolumn{2}{|c|}{$\begin{array}{l}\text { Relative inhibitory } \\
\text { potency }^{a}\end{array}$} \\
\hline & SNA-II & SNA-I \\
\hline D-Gal & 1.0 & 1.0 \\
\hline $\mathrm{Me}-\alpha-\mathrm{D}-\mathrm{Gal}_{p}$ & 0.85 & 0.95 \\
\hline $\mathrm{Me}-\beta-\mathrm{D}-\mathrm{Gal}_{p}$ & 1.6 & 1.73 \\
\hline$p-\mathrm{NO}_{2} \mathrm{Ph}-\alpha-\mathrm{D}-\mathrm{Gal}_{p}$ & 2.6 & 1.2 \\
\hline$p-\mathrm{NO}_{2} \mathrm{Ph}-\beta-\mathrm{D}-\mathrm{Gal}_{p}$ & 4.8 & 10.2 \\
\hline 2-Deoxy-D-Gal & 2.3 & 0.46 \\
\hline D-Fucose & 1.3 & 0.44 \\
\hline D-GalNAc & 32.2 & 1.2 \\
\hline Me- $\alpha-\mathrm{D}-\mathrm{GalNAc}$ & 67.4 & 1.9 \\
\hline $\mathrm{Me}-\beta$-D-GalNAc & 76.3 & 2.6 \\
\hline$p-\mathrm{NO}_{2} \mathrm{Ph}-\alpha-\mathrm{D}-\mathrm{G}$ alNAc $c_{p}$ & 79.5 & 3.7 \\
\hline$p-\mathrm{NO}_{2} \mathrm{Ph}-\beta-\mathrm{D}-\mathrm{GalNAc}$ & 152.6 & 55.9 \\
\hline Lactose & 5.8 & 1.6 \\
\hline LacNAc & 2.4 & 2.2 \\
\hline Melibiose & 1.7 & 0.7 \\
\hline Stachyose & 1.7 & 0.7 \\
\hline GalNAc $\alpha 1,2 \mathrm{Gal}-\mathrm{R}$ & 134.9 & n.d. \\
\hline GalNAc $\alpha 1,3 \mathrm{Ga}]$ & 187.1 & 1.2 \\
\hline GalNAc $\alpha 1,6 \mathrm{Gal}$ & 193.3 & 1.7 \\
\hline GalNAc $\beta 1,6 \mathrm{Gal}$ & 85.3 & 2.6 \\
\hline GalNAc $\alpha 1,3 \mathrm{GalNAc}-\mathrm{R}$ & 38.7 & n.d. \\
\hline GalNAc $\alpha 1,3[\mathrm{~L}-\mathrm{Fuc} \alpha 1,2] \mathrm{Gal}$ & 19.3 & n.d. \\
\hline Neu5Ac $\alpha 2,6$ lactose & $b$ & 1583 \\
\hline Neu5Ac $\alpha 2,3$ lactose & $b$ & 82.6 \\
\hline
\end{tabular}

Note. $\mathrm{R}=-\mathrm{O}-\left(\mathrm{CH}_{2}\right)_{8} \mathrm{CO}_{2} \mathrm{CH}_{3}$.

${ }^{a}$ Galactose is normalized to 1.0 (19 and $0.58 \mathrm{mM}$ required for $50 \%$ inhibition of SNA-I-glycophorin (12) and SNA-II-asialoglycophorin, respectively).

${ }^{b}$ See Table IV.

activity for D-GalNAc end groups than for D-Gal terminal units (Table IV). However, the precipitation data showed that SNA-II has great affinity for glycoconjugates and Type 14 pneumococcal polysaccharides having multiple terminal D-Gal groups.

Among the galactose $/ \mathrm{N}$-acetyl-galactosamine-specific lectins that have been reported, Wistaria floribunda hemagglutinin displays a sugar binding specificity similar to SNA-II. Although $W$. floribunda hemagglutinin has greater affinity for GalNAc than Gal (26), this lectin reacted strongly with Smith-degraded blood group Type A substance and desialyzed fetuin both of which are rich in terminal galactosyl groups. Baker $e t$ al. suggested that a glycoconjugate must contain a number of clustered available reactive glycan structures in order to precipitate with $W$. floribunda hemagglutinin (27). On the contrary, SNA-II did not react with desialyzed fetuin or desialyzed $\alpha_{1}$-acid glycoprotein. These data suggest that SNA-II has a different fine sugar binding specificity than $W$. floribunda hemagglutinin. We already noted above that SNA-II had great affinity for asialo-glycophorin, asialo-laminin, and Type 14 pneumococcal polysaccharide, all of which have multiple terminal $\beta$-Dgalactosyl groups. In fact, Type 14 pneumococcal polysaccharide possesses $25 \% \beta$-D-Gal terminal residues per molecule and there are $15 \% \beta$-D-Gal residues present in asialo-glycophorin. Knibbs et al. reported that the terminal $\beta$-D-Gal residues of laminin increased greatly following treatment with neuraminidase (28). We suggest that these multiple $\beta$-D-Gal residues play an important role in the precipitin reaction with SNA-II, resulting in a cumulative effect of the interaction of the SNA-II with these multiple $\beta$-D-galactosyl groups.

The best oligosaccharide inhibitors of SNA-II-asialoglycophorin precipitation were disaccharide units consisting of GalNAc linked $\alpha$ to the C-2, C-3, or C-6 hydroxyl group of galactose. On the other hand, the Forssman hapten (GalNAc $\alpha 1-3 \mathrm{GalNAc}$ ) was 5 times poorer than GalNAc $\alpha 1-3 \mathrm{Gal}$. This result suggests that the $N$ acetyl group of the penultimate GalNAc group may act to sterically inhibit binding. Interestingly, the blood group Type A trisaccharide, GalNAc $\alpha 1-3$ [L-Fuc $(\alpha 1-2)]$ $\mathrm{Gal}$, was 10 times poorer than GalNAc $\alpha 1-3 \mathrm{Gal}$. The sugar binding site of SNA-II may be composed of two subsites of which the first subsite has high affinity for the GalNAc residue, whereas the penultimate subsite prefers the Gal residue.

The two different lectins isolated from elderberry bark tissue contain similar amino acid compositions; however, the second lectin (SNA-II) has more asparagine/ aspartic acid, glycine, and methionine (Table II). On the other hand the first lectin (SNA-I) consists of a telramer $\left(M_{\mathrm{r}}, 1.4 \times 10^{5}\right)$ having two different subunits whereas SNA-II appears to be a dimeric glycoprotein composed of two identical polypeptide chains (Figs. 2 and 3).

Moreover, both SNA lectins appear to belong to Mäkelä's group II carbohydrates which have binding specificity for Gal/GalNAc among the monosaccharides. SNA-II has greater affinity for D-GalNAc-and $N$-acetylD-galactosaminyl-terminated disaccharides than $\mathrm{D}-\mathrm{Gal}$; these sugars are 30 - to 190 -fold more potent than D-Gal (Table V). On the other hand, SNA-I shows very similar affinity for D-Gal, D-GalNAc, and their respective disaccharides, excepting $p$-nitrophenyl, $\beta$-D-galactoside, and $p$-nitrophenyl $\beta$ - $N$-acetyl-D-galactosaminide. However, SNA-I recognizes the Neu5Ac $\alpha 2-6$ lactose sequence, which is 1600 -fold more potent than Gal and 100 -fold more potent than lactose. On the contrary, Neu5Ac $\alpha 2-$ 6lactose and Neu5Ac $\alpha 2-3$ lactose were poor inhibitors of the SNA-II-asialo-glycophorin precipitation system.

These results may indicate that each lectin plays a different physiological role in the plant. Multiple lectins have been isolated from the same tissue of many plants; still, their physiological function remains unknown. However, studying their chemical and physical proper- 
ties may provide information to clarify their biological functions in plants.

\section{REFERENCES}

1. Hayes, C. E., and Goldstein, I. J. (1974) J. Biol. Chem. 249, 19041914.

2. Shankar Iyer, P. N., Wilkinson, K. D., and Goldstein, I. J. (1976) Arch. Biochem. Biophys. 177, 330-333.

3. Shibata, S., Goldstein, I. J., and Baker, D. A. (1982) J. Biol. Chem. 25 7, 9324-9329.

4. Konami, Y., Yamamoto, K., Tsuji, T., Matsumoto, I., and Osawa, T. (1983) Hoppe-Seyler's Z. Physiol. Chem. 364, 397-405.

5. Rigas, D. A., and Head, C. (1969) Biochem. Biophys. Res. Commun. 34, 633-639.

6. Matsumoto, I., and Osawa, T. (1969) Biochim. Biophys. Acta 194, 180-189.

7. Rudiger, H. (1977) Eur. J. Biochem. 72, 317-322.

8. Tollefsen, S. E., and Kornfeld, R. (1983) J. Biol. Chem. 258, $5165-5171$.

9. Barker, B. E., and Farnes, P. (1967) Nature (London) 215, 659660.

10. Toyoshima, S., Akiyama, Y., Nakano, K., Tonomura, A., and Osawa, T. (1971) Biochemistry 10, 4457-4463.

11. Broekaert, W. F., Nsimba-Lrbaki, M., Peeters, B., and Peumans, W. J. (1984) Biochem. J. 221, 163-169.

12. Shibuya, N., Goldstein, I. J., Broekaert, W. F., Nsimba-Lubaki, M., Peeters, B., and Peumans, W. J. (1987) J. Biol. Chem. 262, $1596-1601$.
13. Kaifu, R., Plantefaber, L. C., and Goldstein, I. J. (1985) Carbohydr. Res. 140, 37-49.

14. Dodge, J. T., Mitchell, C., and Hanahan, D. J. (1963) Arch. Biochem. Biophys. 100, 119-130.

15. Shibata, S., Peters, B., Roberts, D. D., Goldstein, I. J., and Liotta, L. A. (1982) FEBS Lett. 142, 194-198.

16. Lowry, O. H., Rosebrough, N. J., Farr, A. L., and Randall, R. J. (1951) J. Biol. Chem. 193, 265-275.

17. Dubois, M., Gilles, K. A., Hamilton, J. K., Rebers, P. A., and Smith, F. (1956) Anal. Chem. 28, 350-356.

18. Perini, F., and Peters, B. P. (1982) Anal. Biochem. 123, 357-363.

19. Tarr, G. E. (1986) in Methods of Protein Microcharacterization (Shively, J. E., Ed.), pp. 155-194, The Humana Press, Inc., Clifton, NJ.

20. Koop, D. K., Morgan, E. 'T., 'I'arr, G. E., and Coon, M. J. (1982) J. Biol. Chem. 257, 8472-8480.

21. Ebisu, S., Lönngren, J., and Goldstein, I. J. (1977) Carbohydr. Res. 58, 187-191.

22. Reisfeld, R. A., Lewis, U. J., and Williams, D. E. (1962) Nature (London) 195, 281-283.

23. Laemmli, U. K. (1970) Nature (London) 227, 680-685.

24. Funatsu, G., Kimura, M., and Funatsu, M. (1979) Agric. Biol. Chem. 43(10), 2221-2224.

25. Lindberg, B., Lönngren, J., and Powell, D. A. (1977) Carbohydr. Res. 58, 177-186.

26. Sugii, S., and Kabat, E. A. (1980) Biochemistry 19, 1192-1199.

27. Baker, D. A., Sugii, S., Kabat, E. A., Ratcliffe, R. M., Hermentin, P., and Lemieux, R. U. (1983) Biochemistry 22, 2741-2750.

28. Knibbs, R. N., Perini, F., and Goldstein, I. J. (1989) Biochemistry 28, 6379-6392. 